\title{
Long term exposure to ambient fine particulate matter and incidence of stroke: prospective cohort study from the China-PAR project
}

\author{
Keyong Huang, ${ }^{1,2}$ Fengchao Liang, ${ }^{1}$ Xueli Yang, ${ }^{1}$ Fangchao Liu, ${ }^{1}$ Jianxin Li, ${ }^{1}$ Qingyang Xiao, ${ }^{3}$ \\ Jichun Chen, ${ }^{1}$ Xiaoqing Liu, ${ }^{4}$ Jie Cao, ${ }^{1}$ Chong Shen, ${ }^{5}$ Ling Yu, ${ }^{6}$ Fanghong Lu, ${ }^{7}$ Xianping Wu, ${ }^{8}$ \\ Liancheng Zhao, ${ }^{1}$ Xigui Wu, ${ }^{1}$ Ying Li, ${ }^{1}$ Dongsheng Hu, ${ }^{9}$ Jianfeng Huang, ${ }^{1}$ Yang Liu, ${ }^{10}$ \\ Xiangfeng Lu, ${ }^{1}$ Dongfeng Gu${ }^{1,2}$
}

\begin{abstract}
For numbered affiliations see end of the article.

Correspondence to: D Gu gudongfeng@cashq.ac.cn (ORCID 0000-0002-2781-7825)

Additional material is published online only. To view please visit the journal online.

Cite this as: $B M J$ 2019;367:16720 http://dx.doi.org/10.1136/bmj.16720
\end{abstract}

Accepted: 27 November 2019 were observed.

\section{ABSTRACT}

\section{OBJECTIVE}

To study the effect of long term exposure to ambient fine particulate matter of diameter $\leq 2.5 \mu \mathrm{m}\left(\mathrm{PM}_{2.5}\right)$ on the incidence of total, ischemic, and hemorrhagic stroke among Chinese adults.

\section{DESIGN}

Population based prospective cohort study.

SETTING

Prediction for Atherosclerotic Cardiovascular Disease Risk in China (China-PAR) project carried out in 15 provinces across China.

\section{PARTICIPANTS}

117575 Chinese men and women without stroke at baseline in the China-PAR project.

MAIN OUTCOME MEASURES

Incidence of total, ischemic, and hemorrhagic stroke. RESULTS

The long term average $\mathrm{PM}_{2.5}$ level from 2000 to 2015 at participants' residential addresses was $64.9 \mu \mathrm{g} /$ $\mathrm{m}^{3}$, ranging from $31.2 \mu \mathrm{g} / \mathrm{m}^{3}$ to $97.0 \mu \mathrm{g} / \mathrm{m}^{3}$. During 900214 person years of follow-up, 3540 cases of incident stroke were identified, of which $63.0 \%$ $(n=2230)$ were ischemic and $27.5 \%(n=973)$ were hemorrhagic. Compared with the first quarter of exposure to $\mathrm{PM}_{2.5}\left(<54.5 \mu \mathrm{g} / \mathrm{m}^{3}\right)$, participants in the highest quarter $\left(>78.2 \mu \mathrm{g} / \mathrm{m}^{3}\right)$ had an increased risk of incident stroke (hazard ratio 1.53, $95 \%$ confidence interval 1.34 to 1.74$)$, ischemic stroke $(1.82,1.55$ to

\section{WHAT IS ALREADY KNOWN ON THIS TOPIC}

The association between long term exposure to ambient $\mathrm{PM}_{2.5}$ and incidence of stroke has been well documented in North America and Europe, with most studies having relatively low $\mathrm{PM}_{2.5}$ concentrations (typically $\leq 25 \mu \mathrm{g} / \mathrm{m}^{3}$ )

However, evidence is lacking about the association between long term exposure to $\mathrm{PM}_{2.5}$ and incidence of stroke at high ambient concentrations, usually found in low and middle income countries

\section{WHAT THIS STUDY ADDS}

Long term exposure to ambient $\mathrm{PM}_{2.5}$ at relatively high concentrations is positively associated with risk of incident stroke and its major subtypes

The results suggest almost linear exposure-response relations between exposure to $\mathrm{PM}_{2.5}$ and incidence of stroke, covering a wide range of $\mathrm{PM}_{2.5}$ levels

$\left(31.2-97.0 \mu \mathrm{g} / \mathrm{m}^{3}\right)$

These findings are important for environmental and health policies related to air pollution and stroke prevention in China, as well as for other low and middle income countries

2.14), and hemorrhagic stroke (1.50, 1.16 to 1.93). For each increase of $10 \mu \mathrm{g} / \mathrm{m}^{3}$ in $\mathrm{PM}_{2.5}$ concentration, the increased risks of incident stroke, ischemic stroke, and hemorrhagic stroke were $13 \%(1.13,1.09$ to 1.17$), 20 \%(1.20,1.15$ to 1.25$)$, and $12 \%(1.12$, 1.05 to 1.20$)$, respectively. Almost linear exposureresponse relations between long term exposure to $\mathrm{PM}_{2.5}$ and incident stroke, overall and by its subtypes,

\section{CONCLUSIONS}

This study provides evidence from China that long term exposure to ambient $\mathrm{PM}_{2.5}$ at relatively high concentrations is positively associated with incident stroke and its major subtypes. These findings are meaningful for both environmental and health policy development related to air pollution and stroke prevention, not only in China, but also in other low and middle income countries.

\section{Introduction}

Ambient air pollution, especially fine particulate matter $\left(\mathrm{PM}_{2.5}\right.$, particles with an aerodynamic diameter of $\leq 2.5 \mu \mathrm{m}$ ) pollution, is a major public health concern in China and worldwide. ${ }^{1}$ More than $90 \%$ of the world's population lives in regions where air quality exceeds the World Health Organization's annual mean $\mathrm{PM}_{2.5}$ standard, set at $10 \mu \mathrm{g} / \mathrm{m}^{3}{ }^{3}$. The Global Burden of Disease Study estimated that 2.94 million deaths were attributable to ambient $\mathrm{PM}_{2.5}$ air pollution globally in 2017 , and about $48 \%$ of these were from ischemic heart diseases and strokes. ${ }^{2}$ Moreover, the estimated disease burden of ambient $\mathrm{PM}_{2.5}$ pollution was much higher in low and middle income countries such as China and India. ${ }^{3}$

Although previous studies of short term exposure (eg, over a few days) to ambient $\mathrm{PM}_{2.5}$ have reported increased risks of hospital admission for stroke in China, evidence of the accumulated damage on cardiovascular health caused by long term exposure to air pollution was limited. Several cohort studies have investigated the association between long term exposure to ambient $\mathrm{PM}_{2.5}$ over multiple years and incidence of stroke..$^{4-7}$ Most of these studies, however, were conducted in North America and Europe, where the average ambient $\mathrm{PM}_{2.5}$ levels have historically been lower than $25 \mu \mathrm{g} / \mathrm{m}^{3}$. $^{2.5}$ Consequently, these studies provided limited insight into the health effects of exposure to extreme $\mathrm{PM}_{2.5}$ air pollution, which were generally found in low and middle income countries. ${ }^{3}$ In 
addition, the cause and risk profiles of ischemic stroke versus hemorrhagic stroke are different, highlighting the importance of considering these events separately. ${ }^{4}$ However, few studies have distinguished between the effects of long term exposure to $\mathrm{PM}_{2.5}$ on ischemic and hemorrhagic stroke.

Epidemiological studies focusing on the chronic health effects of exposure to ambient $\mathrm{PM}_{2.5}$ in China have been hindered owing to the absence of routine air quality monitoring networks before $2013 .{ }^{8}$ To support such studies, several spatiotemporal statistical models based on satellite retrieved aerosol optical depth have been developed to provide long term estimates of $\mathrm{PM}_{2.5}{ }^{89}$ Combining monitoring data and satellite based $\mathrm{PM}_{2.5}$ estimations has now made it possible to provide accurate $\mathrm{PM}_{2.5}$ exposure assessment for epidemiological studies. Existing studies pertaining to the adverse health impacts of $\mathrm{PM}_{2.5}$ in China have, however, primarily assessed exposure to $\mathrm{PM}_{2.5}$ at relatively coarse spatial resolution $(\mathrm{eg}, 10 \times 10 \mathrm{~km}),{ }^{2.5} 11$ which may have failed to capture fine scale $\mathrm{PM}_{2.5}$ gradients thereby leading to misclassification of exposure.

We investigated the association between long term exposure to ambient $\mathrm{PM}_{2.5}$ and incidence of stroke, overall and by subtypes, using data from satellite based high quality $\mathrm{PM}_{2.5}$ estimates at $1 \times 1 \mathrm{~km}$ spatial resolution combined with the Prediction for Atherosclerotic Cardiovascular Disease Risk in China (China-PAR)-an established prospective project.

\section{Methods}

\section{Study population}

The China-PAR project was established to investigate the distribution patterns of cardiovascular diseases and associated risk factors in the general Chinese population. A detailed description of the design is published elsewhere. ${ }^{1213}$ Briefly, the China-PAR project was carried out in 15 Chinese provinces and included four subcohorts: China MUCA (1992-94) (China Multi-Center Collaborative Study of Cardiovascular Epidemiology), ${ }^{14}$ China MUCA (1998), ${ }^{15}$ InterASIA (International Collaborative Study of Cardiovascular Disease in Asia), ${ }^{16}$ and CIMIC (Community Intervention of Metabolic Syndrome in China and Chinese Family Health Study). ${ }^{12}$ From 1992 to 2008, a total of 127840 Chinese adults ( $\geq 18$ years) were initially enrolled for the baseline examinations. The subcohorts were last followed-up between 2012 and 2015 (see supplementary file for details).

\section{Data collection}

For all subcohorts we used identical methods at baseline and follow-up surveys. Trained healthcare staff used a standardized questionnaire under strict quality control to collect information on personal characteristics, medical history, and lifestyle risk factors. Smoking was defined as having consumed at least 400 cigarettes or $500 \mathrm{~g}$ of tobacco leaves throughout the lifetime, or at least one cigarette daily for one year or more. We categorized participants into never, former, and current smokers. Current smokers were defined as those who were smoking at the time of survey, and former smokers were those who ever smoked but had quitted at the time of survey. Alcohol consumption was defined as drinking alcohol at least once weekly during the past year. Education was classified as high school or above ( $\geq 10$ years of education received) or less than high school $(<10$ years). Work related physical activity was categorized into vigorous or moderate activity, light or sedentary activity, or no job or retirement based on participants' occupation. Body weight and height were measured to the nearest $0.5 \mathrm{~kg}$ and $0.5 \mathrm{~cm}$, respectively, with participants wearing only lightweight clothing and no shoes. Body mass index (BMI) was calculated as weight $(\mathrm{kg}) /\left(\right.$ height $\left.(\mathrm{m})^{2}\right)$.

Trained healthcare practitioners measured participants' blood pressure during clinic or home visits in accordance with the protocol recommended by the American Heart Association. ${ }^{17}$ Three measurements were obtained after participants had rested for five minutes. For this analysis we used the average of the three readings. In addition, blood samples were obtained from participants after a prescribed 10 hours of fasting to measure both serum glucose and lipid levels.

Information on stroke incidence during the followup period was collected by interviewing study participants or their proxies, and further checking hospital records or death certificates for verification. Local investigators initially recorded fatal and nonfatal stroke events. The central adjudication committee at Fuwai Hospital (Beijing, China) reviewed all medical and death records and determined the final diagnosis. Two adjudication committee members verified events independently, and discrepancies were resolved by discussion involving additional committee members. Causes of death were coded according to ICD-10 (international classification of diseases, 10th revision). For this analysis, incident stroke was defined as a confirmed diagnosis of first ever fatal or nonfatal stroke event during follow-up (I60-I69). We also classified subtypes of stroke: ischemic stroke (I63), hemorrhagic stroke (I60-I62), and unspecified stroke (I64-I69).

Written informed consent was obtained from each participant before data collection.

\section{Exposure assessment}

We used a satellite based spatiotemporal model to estimate ambient $\mathrm{PM}_{2.5}$ levels at $1 \times 1 \mathrm{~km}$ spatial resolution. A detailed methodology of this model is published elsewhere. ${ }^{18} 19$ Briefly, we used machine learning algorithms to estimate ground level $\mathrm{PM}_{2.5}$ concentrations in China based on satellite retrieved aerosol optical depth retrievals from US National Aeronautics and Space Administration, land use information, roads, meteorology, and population density data. To ensure a high spatiotemporal coverage and minimize the bias of $\mathrm{PM}_{2.5}$ estimations, we used a multiple imputation method to fill 
missing aerosol optical depth values. Compared with our previous $\mathrm{PM}_{2.5}$ prediction model, ${ }^{18}$ we improved the model for the current study by using the $1 \times 1 \mathrm{~km}$ resolution aerosol optical depth data retrieved through a Multi-Angle Implementation of Atmospheric Correction algorithm ${ }^{20}$ and estimated monthly $\mathrm{PM}_{2.5}$ concentrations at $1 \times 1 \mathrm{~km}$ resolution. We then validated this model using ground $\mathrm{PM}_{2.5}$ measurements from the China Environmental Monitoring Center (www.cnemc.cn/). We obtained an overall 10-fold cross validation $\mathrm{R}^{2}$ of 0.93 at the monthly level and 0.95 at the annual level. To assess the accuracy of predicting historical $\mathrm{PM}_{2.5}$ concentrations (before 2013), we compared model predictions with available monitoring data from Hong Kong, Taiwan, and the US Embassy in Beijing, Shanghai, and Guangzhou, and the prediction $\mathrm{R}^{2}$ and root mean squared error were 0.80 and $8.90 \mu \mathrm{g} / \mathrm{m}^{3}$, respectively at the annual level.

Based on this model, we obtained monthly $\mathrm{PM}_{2.5}$ levels from 2000 to 2015 in China. Each participant's residential address was geocoded into latitude and longitude data. To account for participants who changed address, in the main analyses we calculated a time weighted average exposure to $\mathrm{PM}_{2.5}$ from 2000 to 2015 for each participant, with weights defined as the duration spent at each residence. In addition, we also calculated the annual $\mathrm{PM}_{2.5}$ level as a time varying exposure in a sensitivity analysis, taking into account the temporal variations of $\mathrm{PM}_{2.5}$ during our study period.

\section{Statistical analysis}

We present the baseline characteristics of the included participants as means with corresponding standard deviations for continuous variables and as percentages for categorical variables.

Person years of follow-up were calculated from the date of initial examination or 1 January 2000 (for participants enrolled before 2000) until the date of stroke occurrence, death, or the date of most recent follow-up, whichever occurred first. Stratified Cox proportional hazards regression models with stratums defined as subcohorts were used to examine the association between long term exposure to $\mathrm{PM}_{2.5}$ and stroke, which were commonly adopted regression models in previous epidemiological studies. ${ }^{21} 22 \mathrm{We}$ assessed the proportional hazards assumption by evaluating the weighted Schoenfeld residuals, ${ }^{23}$ and no violations were observed $(P>0.05)$. Participants were analyzed in one dataset to ensure sufficient statistical power and wider gradients of exposure to $\mathrm{PM}_{2.5}$. We categorized participants into four groups according to quarters of exposure to $\mathrm{PM}_{2.5}$ (ie, 31.2$54.5 \mu \mathrm{g} / \mathrm{m}^{3}$, 54.6-59.6 $\mathrm{\mu g} / \mathrm{m}^{3}$, 59.7-78.2 $\mu \mathrm{g} / \mathrm{m}^{3}$, and 78.3-97.0 $\mu \mathrm{g} / \mathrm{m}^{3}$ ). When $\mathrm{PM}_{2.5}$ was considered a continuous variable, we reported the hazard ratio of incident stroke for each $10 \mu \mathrm{g} / \mathrm{m}^{3}$ increment in $\mathrm{PM}_{2.5}$ level. An exposure-response curve between $\mathrm{PM}_{2.5}$ concentration and incident stroke was plotted using a penalized spline with two degrees of freedom. We evaluated the Akaike Information Criterion to decide on degrees of freedom. ${ }^{24}$

In the multivariate adjusted Cox models, we included covariates that we hypothesized a priori could potentially confound the relation between $\mathrm{PM}_{2.5}$ concentration and stroke. We included three models using covariates collected at baseline. ${ }^{611} 2526$ In model 1, we adjusted for age and sex. In model 2, we additionally adjusted for urbanization (urban or rural area) and geographical region. To account for the residual confounders related to spatial variation in stroke onset, we included seven geographic regionsnorth, east, north eastern, south, central, south western, and north western. In model 3, we further adjusted for smoking status (never, former, or current smoker), alcohol intake (yes or no), education level (less than high school, or high school or above), work related physical activity (vigorous or moderate, light or sedentary, no job or retirement), body mass index, and hypertension (yes or no). Model 3 was used as the main model in further analyses.

Based on previous evidence of possible effect modifications, ${ }^{5} 6$ we conducted subgroup analyses by age, sex, cigarette smoking, alcohol intake, BMI, abdominal obesity, hypertension, diabetes, education level, and urbanization using model 3. We fitted separate Cox models for each subgroup and obtained subgroup specific effect estimates of $\mathrm{PM}_{2.5}$. Then we performed a two sample $\mathrm{z}$ test to assess whether the effect estimates between subgroups were statistically different. $^{212728}$

Based on model 3, we performed several sensitivity analyses by further adjusting for baseline diabetes and total cholesterol levels, and alternately by excluding those who had coronary heart disease at the baseline examination, or simply by excluding incident stroke events that occurred during the first year of followup. To assess the confounding role of neighborhood socioeconomic status, we collected the information about county level averaged years of education as a surrogate for socioeconomic status, and we further adjusted for it in the Cox model. Since the baseline information was collected several years before 2000 for the China MUCA (1992-94) subcohort, we conducted a sensitivity analysis by excluding this subcohort. Moreover, to investigate the potential confounding effect of smoking dose, we conducted a sensitivity analysis by further adjusting for smoking pack year history in three of the subcohorts; the China MUCA (1992-94) subcohort had no information on smoking dose.

To consider the temporal variation of $\mathrm{PM}_{2.5}$ concentrations, we conducted a sensitivity analysis by using annual $\mathrm{PM}_{2.5}$ level as a time varying exposure in the survival model. In each annual scale of this model, all covariates were updated using the latest followup information. We also conducted an additional sensitivity analysis by using baseline two year average $\mathrm{PM}_{2.5}$ levels as the long term exposure (ie, average $\mathrm{PM}_{2.5}$ exposures from 2000 to 2001 for the China MUCA (1992-94), China MUCA (1998), and InterASIA 




Fig 1 | Flowchart of study participants included and excluded in analyses. ChinaPAR=Prediction for Atherosclerotic Cardiovascular Disease Risk in China project

cohorts; averages from 2007 to 2008 for the CIMIC cohort), and we re-ran the Cox models.

Statistical analyses were performed using SAS 9.4 (SAS Institute, Cary, NC) and R software, version 3.4.2 (R Foundation for Statistical Computing, Vienna, Austria). Tests were two sided with statistical significance set at $\mathrm{P}<0.05$.

\section{Patient and public involvement}

Patients and members of the public were not involved in setting the research question or the outcome measures, nor were they involved in design and implementation of the study. The results of physical examination and biochemical test were disseminated to each study participant.

\section{Results}

Of the original participants in China-PAR project, 119388 (93.4\%) were followed-up successfully. Because the $\mathrm{PM}_{2.5}$ exposure data were available since 2000, we used the follow-up information after that year. Therefore, we excluded 1548 participants with previous stroke and 165 deceased participants before 2000. A further 100 participants were excluded because of missing residential details, leaving 117575 participants for the current analysis (fig 1).

Figure 2 shows the cities in which participants resided at baseline. The average $\mathrm{PM}_{2.5}$ level from 2000 until 2015 at the participants' residential address was $64.9 \mu \mathrm{g} / \mathrm{m}^{3}$, ranging from $31.2 \mu \mathrm{g} / \mathrm{m}^{3}$ to $97.0 \mu \mathrm{g} / \mathrm{m}^{3}$. Table 1 presents the baseline characteristics, overall and according to quarters of exposure to $\mathrm{PM}_{2.5}$. At baseline the mean age of participants was 50.9 years, 41.0\% were men, and $23.9 \%$ were current smokers. Participants with higher exposure to $\mathrm{PM}_{2.5}$ were less often classified as current smokers and tended to have higher BMI, systolic blood pressure, and diastolic blood pressure levels.

During 900214 person years of follow-up, 3540 cases of incident stroke were identified, with an incidence rate of 393 cases per 100000 person years. Of the total number of stroke cases, 63.0\% $(n=2230)$ were classified as ischemic stroke, $27.5 \%(n=973)$ were classified as hemorrhagic stroke, 8.2\% $(n=291)$ were considered of unknown subtype, and $1.3 \%(n=46)$ were classified as both ischemic and hemorrhagic stroke subtypes. Table 2 presents the crude and multivariate adjusted hazard ratios and 95\% confidence intervals for the association of incident stroke with long term exposure to $\mathrm{PM}_{2.5}$. In the age and sex adjusted model, higher exposure to $\mathrm{PM}_{2.5}$ was significantly associated with an increased risk of stroke $(\mathrm{P}<0.001)$. After multivariate adjustment, we observed similar results,

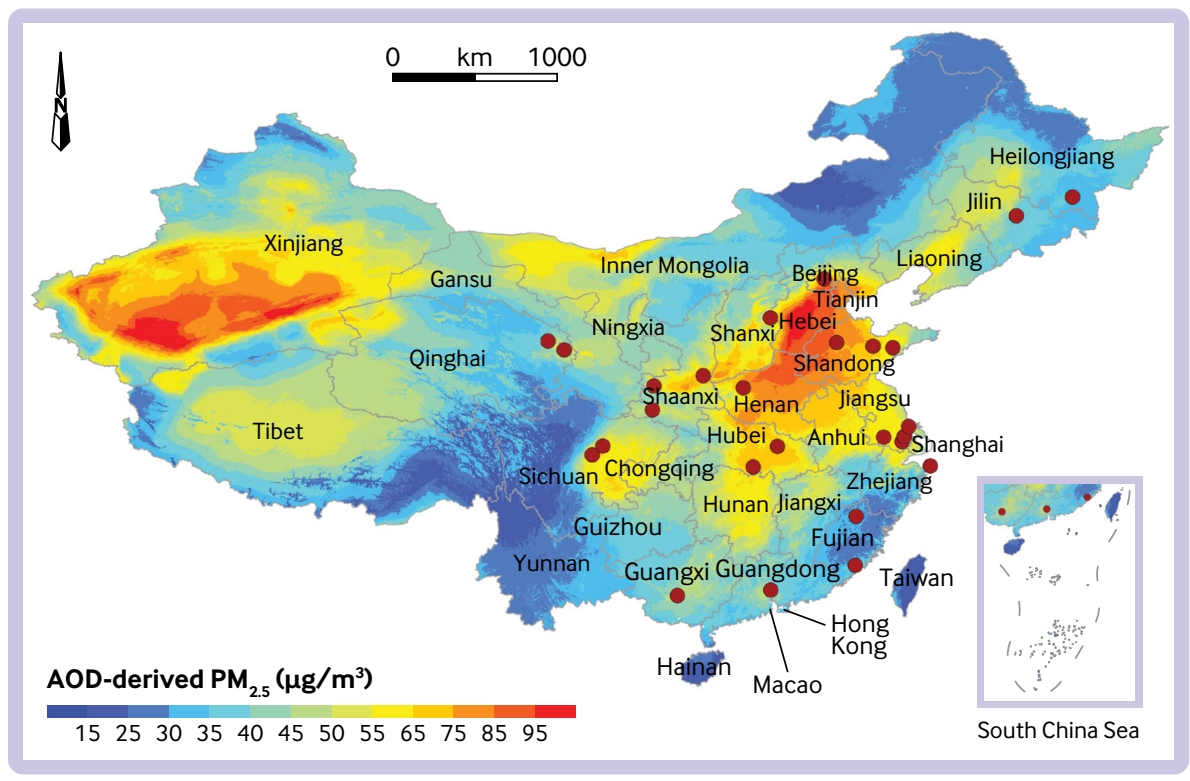

Fig 2 | Average fine particulate matter of diameter $\leq 2.5 \mu \mathrm{m}\left(\mathrm{PM}_{2.5}\right)$ levels in China, 2000-15. Red solid circles denote cities where study participants resided at baseline. $A O D=$ aerosol optical depth 


\begin{tabular}{|c|c|c|c|c|c|}
\hline \multirow[b]{2}{*}{ Characteristics } & \multirow[b]{2}{*}{ Total cohort } & \multicolumn{4}{|c|}{ Quarters of $\mathrm{PM}_{2.5}$ levels } \\
\hline & & $\begin{array}{l}\text { First } \\
\left(31.2-54.5 \mu \mathrm{g} / \mathrm{m}^{3}\right)\end{array}$ & $\begin{array}{l}\text { Second } \\
\left(54.6-59.6 \mu \mathrm{g} / \mathrm{m}^{3}\right)\end{array}$ & $\begin{array}{l}\text { Third } \\
\left(59.7-78.2 \mu \mathrm{g} / \mathrm{m}^{3}\right)\end{array}$ & $\begin{array}{l}\text { Fourth } \\
\left(78.3-97.0 \mu \mathrm{g} / \mathrm{m}^{3}\right)\end{array}$ \\
\hline No of participants & 117575 & 28540 & 30751 & 28951 & 29333 \\
\hline Mean (SD) $\mathrm{PM}_{2.5}$ level $\left(\mu \mathrm{g} / \mathrm{m}^{3}\right)$ & $64.9(14.2)$ & $48.3(5.8)$ & $57.0(1.6)$ & $71.1(7.7)$ & $83.3(1.8)$ \\
\hline Mean (SD) age at baseline (years) & $50.9(11.8)$ & $50.6(10.3)$ & $51.2(12.9)$ & $50.4(12.3)$ & $51.4(11.6)$ \\
\hline Men & $48225(41.0)$ & $12279(43.0)$ & $12110(39.4)$ & $11997(41.4)$ & $11839(40.4)$ \\
\hline \multicolumn{6}{|l|}{ Smoking status: } \\
\hline Never & $84797(72.4)$ & $19867(69.9)$ & $22156(72.7)$ & $20519(71.1)$ & $22255(76.0)$ \\
\hline Former & $4358(3.7)$ & $1148(4.0)$ & $979(3.2)$ & $1472(5.1)$ & $759(2.6)$ \\
\hline Current & $27921(23.9)$ & $7416(26.1)$ & $7334(24.1)$ & 6889 (23.9) & $6282(21.4)$ \\
\hline \multicolumn{6}{|l|}{ Education: } \\
\hline Less than high school & $100364(85.8)$ & $23252(82.3)$ & $27300(89.3)$ & $24294(84.1)$ & $25518(87.1)$ \\
\hline High school or above & $16650(14.2)$ & $5012(17.7)$ & $3285(10.7)$ & $4589(15.9)$ & $3764(12.9)$ \\
\hline \multicolumn{6}{|l|}{ Work related physical activity: } \\
\hline Vigorous or moderate level & $65201(55.6)$ & $17100(60.2)$ & $16414(53.6)$ & $15910(55.1)$ & $15777(53.9)$ \\
\hline Light or sedentary level & $33159(28.3)$ & $8628(30.4)$ & $9152(29.9)$ & $7772(26.9)$ & $7607(26.0)$ \\
\hline No job or retirement & $18829(16.1)$ & $2673(9.4)$ & $5035(16.5)$ & $5218(18.1)$ & $5903(20.2)$ \\
\hline Urban residence & $14456(12.3)$ & $6698(23.5)$ & $972(3.2)$ & $3473(12.0)$ & $3313(11.3)$ \\
\hline Alcohol drinker & $22924(19.5)$ & $7300(25.6)$ & $6299(20.5)$ & $3931(13.6)$ & $5394(18.4)$ \\
\hline Mean (SD) body mass index & $23.6(3.6)$ & $22.8(3.5)$ & $23.0(3.4)$ & $23.8(3.5)$ & $24.6(3.7)$ \\
\hline Mean (SD) systolic blood pressure (mm Hg) & $127.6(21.2)$ & $121.4(18.5)$ & $126.9(19.2)$ & $126.7(21.0)$ & $135.2(23.3)$ \\
\hline Mean (SD) diastolic blood pressure $(\mathrm{mm} \mathrm{Hg})$ & $78.8(11.7)$ & $75.8(11.2)$ & $77.6(11.1)$ & $78.6(11.4)$ & $83.2(11.8)$ \\
\hline Diabetes & $6137(5.5)$ & $967(3.8)$ & $1289(4.5)$ & $1947(7.0)$ & $1934(6.7)$ \\
\hline Hypercholesterolemia & $5014(4.5)$ & $1649(6.5)$ & $766(2.7)$ & $1257(4.4)$ & $1342(4.7)$ \\
\hline
\end{tabular}

with hazard ratios of 1.11 (95\% confidence interval 0.98 to 1.26 ), 1.30 (1.13 to 1.49 ), and 1.53 (1.34 to 1.74) for participants exposed to the second, third, and fourth quarters of $\mathrm{PM}_{2.5}$ concentrations, respectively.

Each $10 \mu \mathrm{g} / \mathrm{m}^{3}$ increase in $\mathrm{PM}_{2.5}$ was significantly associated with a $13 \%$ increase in stroke incidence
(1.13, 1.09 to 1.17) after multivariate adjustment using model 3. In the analyses for stroke subtypes, incidence of both ischemic stroke and hemorrhagic stroke were significantly associated with long term exposure to $\mathrm{PM}_{2.5}$. Each $10 \mu \mathrm{g} / \mathrm{m}^{3}$ increase in $\mathrm{PM}_{2.5}$ was associated with a $20 \%$ increase in incidence of ischemic stroke

\begin{tabular}{|c|c|c|c|c|c|c|}
\hline \multirow[b]{2}{*}{ Characteristics } & \multicolumn{4}{|c|}{ Quarters of $\mathrm{PM}_{2.5}$ levels } & \multirow[b]{2}{*}{$P$ trend } & \multirow[b]{2}{*}{$\begin{array}{l}\mathrm{PM}_{2.5} \text { per } 10 \mu \mathrm{g} / \mathrm{m}^{3} \\
\text { increment }\end{array}$} \\
\hline & $\begin{array}{l}\text { First } \\
\left(31.2-54.5 \mu \mathrm{g} / \mathrm{m}^{3}\right)\end{array}$ & $\begin{array}{l}\text { Second } \\
\left(54.6-59.6 \mu \mathrm{g} / \mathrm{m}^{3}\right)\end{array}$ & $\begin{array}{l}\text { Third } \\
\left(59.7-78.2 \mu \mathrm{g} / \mathrm{m}^{3}\right)\end{array}$ & $\begin{array}{l}\text { Fourth } \\
\left(78.3-97.0 \mu \mathrm{g} / \mathrm{m}^{3}\right)\end{array}$ & & \\
\hline \multicolumn{7}{|l|}{ Stroke incidence } \\
\hline Person years & 270110 & 212760 & 216536 & 200808 & - & - \\
\hline No of cases & 825 & 718 & 995 & 1002 & - & - \\
\hline Incidence ratet & 305.4 & 337.5 & 459.5 & 499.0 & - & - \\
\hline Model 1‡ & 1.00 & $1.06(0.95$ to 1.17$)$ & 1.80 (1.63 to 1.98$)$ & 2.02 (1.83 to 2.22$)$ & $<0.001$ & $1.26(1.23$ to 1.29$)$ \\
\hline Model $2 \S$ & 1.00 & $1.20(1.06$ to 1.35$)$ & $1.54(1.34$ to 1.76$)$ & 1.95 (1.72 to 2.22$)$ & $<0.001$ & $1.22(1.18$ to 1.27$)$ \\
\hline Model 3ी & 1.00 & 1.11 (0.98 to 1.26$)$ & 1.30 (1.13 to 1.49$)$ & $1.53(1.34$ to 1.74$)$ & $<0.001$ & 1.13 (1.09 to 1.17$)$ \\
\hline \multicolumn{7}{|l|}{ Ischemic stroke } \\
\hline Person years & 270799 & 213025 & 217093 & 201306 & - & - \\
\hline No of cases & 495 & 435 & 627 & 719 & - & - \\
\hline Incidence ratet & 182.8 & 204.2 & 288.8 & 357.2 & - & - \\
\hline Model $1 \ddagger$ & 1.00 & $1.10(0.97$ to 1.26$)$ & 2.09 (1.85 to 2.37$)$ & $2.62(2.32$ to 2.95$)$ & $<0.001$ & 1.35 (1.31 to 1.39$)$ \\
\hline Model $2 \S$ & 1.00 & 1.18 (1.01 to 1.38$)$ & 1.77 (1.49 to 2.11$)$ & 2.31 (1.97 to 2.71$)$ & $<0.001$ & 1.29 (1.24 to 1.35$)$ \\
\hline Model 39 & 1.00 & $1.10(0.94$ to 1.29$)$ & $1.49(1.25$ to 1.77$)$ & $1.82(1.55$ to 2.14$)$ & $<0.001$ & $1.20(1.15$ to 1.25$)$ \\
\hline \multicolumn{7}{|c|}{ Hemorrhagic stroke } \\
\hline Person years & 271437 & 213425 & 218300 & 203168 & - & - \\
\hline No of cases & 264 & 216 & 290 & 249 & - & - \\
\hline Incidence ratet & 97.3 & 101.2 & 132.8 & 122.6 & - & - \\
\hline Model $1 \ddagger$ & 1.00 & 0.97 (0.81 to 1.18$)$ & 1.41 (1.19 to 1.68$)$ & 1.39 (1.16 to 1.66$)$ & $<0.001$ & 1.14 (1.09 to 1.19$)$ \\
\hline Model $2 \S$ & 1.00 & $1.31(1.04$ to 1.66$)$ & 1.64 (1.27 to 2.12$)$ & 1.99 (1.56 to 2.55$)$ & $<0.001$ & $1.23(1.15$ to 1.31$)$ \\
\hline Model 3ी & 1.00 & 1.21 (0.94 to 1.54$)$ & 1.40 (1.07 to 1.82$)$ & $1.50(1.16$ to 1.93$)$ & $<0.001$ & $1.12(1.05$ to 1.20$)$ \\
\hline
\end{tabular}


$(1.20,1.15$ to 1.25$)$ and a $12 \%$ increase in incidence of hemorrhagic stroke (1.12, 1.05 to 1.20$)$.

Supplementary figure S1 shows the association of exposure to $\mathrm{PM}_{2.5}$ with incident stroke and related subtypes stratified by selected characteristics. The effect of $\mathrm{PM}_{2.5}$ on stroke incidence did not vary by individual risk factors. For ischemic stroke, however, stronger associations seemed to exist among elderly people than among younger people $(\mathrm{P}=0.05$ for effect modification). In addition, for ischemic stroke stronger effects of $\mathrm{PM}_{2.5}$ were observed in normal weight participants compared with overweight participants ( $\mathrm{P}=0.02$ for effect modification), whereas no effect modification was observed for abdominal obesity.

Figure 3 illustrates the exposure-response curve for the association between long term exposure to $\mathrm{PM}_{2.5}$
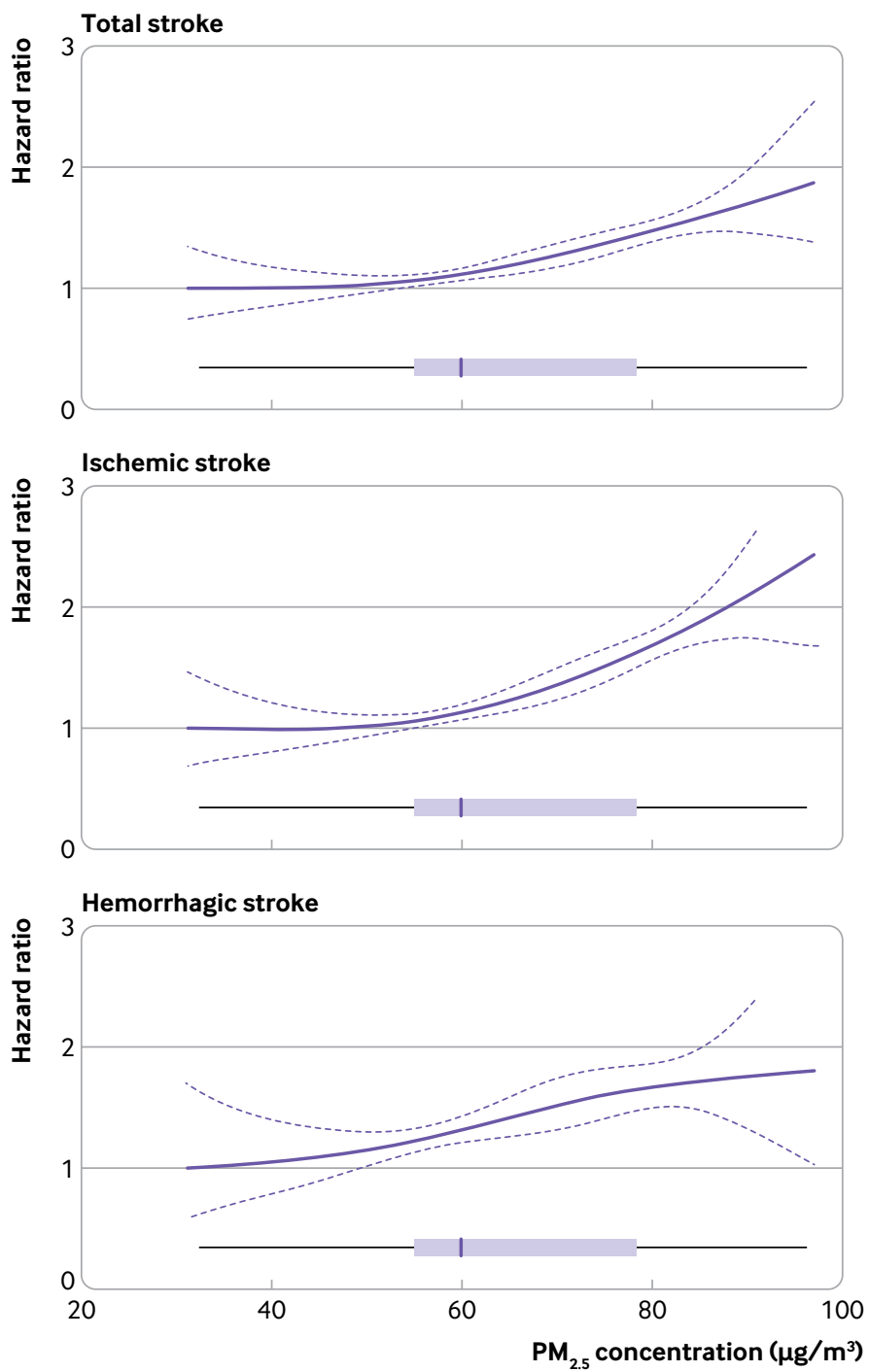

Fig 3 | Exposure-response relations between long term exposure to fine particulate matter of diameter $\leq 2.5 \mu \mathrm{m}\left(\mathrm{PM}_{2.5}\right)$ and incidence of total stroke, ischemic stroke, and hemorrhagic stroke among Chinese adults, using a penalized spline function with two degrees of freedom. Hazard ratios were estimated by comparing to a reference value of $31.2 \mu \mathrm{g} / \mathrm{m}^{3}$. Solid line represents point estimate and dashed lines represent $95 \%$ confidence intervals. Boxplot represents distribution of $\mathrm{PM}_{2.5}$ exposure levels for participants and incident risk of all stroke, ischemic stroke, and hemorrhagic stroke. The exposure-response curves were observed to be monotonic and almost linear across the range of $\mathrm{PM}_{2.5}$ concentrations in the study population.

Table 3 shows the results of several sensitivity analyses based on model 3. Overall, no substantial changes occurred in the effect estimates of $\mathrm{PM}_{2.5}$ across the various analyses. When further adjustment was made for the county level averaged years of education, the effect estimates were 1.15 (1.11 to 1.19) for total stroke, 1.24 (1.18 to 1.30 ) for ischemic stroke, and 1.13 (1.06 to 1.21) for hemorrhagic stroke. When using annual mean $\mathrm{PM}_{2.5}$ concentrations as timevarying exposures or baseline two year average $\mathrm{PM}_{2.5}$ levels as long term exposures in the Cox model, similar associations with the main analyses were obtained. Exclusion of the China MUCA (1992-94) subcohort did not substantially influence the results. Furthermore, in the analysis with smoking pack year history considered in the three subcohorts with available information on smoking dose, the associations between $\mathrm{PM}_{2.5}$ level and incident stroke were observed to be not significantly different from those fitted using model 3. Adjustment for baseline diabetes and total cholesterol levels did not substantially alter the results either. In addition, the results remained stable after excluding those with a diagnosis of coronary heart disease at baseline examination or when excluding those with incident stroke events occurring within the first year of follow-up.

\section{Discussion}

In this prospective cohort study in China we found significantly higher risks of incident stroke, ischemic stroke, and hemorrhagic stroke associated with long term exposure to high $\mathrm{PM}_{2.5}$ levels. We identified almost linear exposure-response relations between $\mathrm{PM}_{2.5}$ level and incident stroke and both subtypes separately.

\section{Comparison with other studies}

The results of previous studies on the long term effects of exposure to $\mathrm{PM}_{2.5}$ on stroke incidence have been inconclusive..$^{4-6} 29$ 30 Our findings highlighted a positive effect between long term exposure to $\mathrm{PM}_{2.5}$ and incident stroke that were consistent with findings from the European Study of Cohorts for Air Pollution Effects project and the Women's Health Initiative. ${ }^{56}$ However, analyses of the Health Professionals cohort and other cohorts from UK and Sweden failed to identify statistically significant effects of air pollution on incidence of stroke. ${ }^{29-31}$

The magnitude of effects of $\mathrm{PM}_{2.5}$ on stroke incidence in the current study (hazard ratio 1.13, 95\% confidence interval 1.09 to 1.17 , per $10 \mu \mathrm{g} / \mathrm{m}^{3}$ increment) was similar to that found in a recent meta-analysis of separate cohort studies in North America and Europe (ie, hazard ratio $1.064,95 \%$ confidence interval 1.021 to 1.109 ) per $5 \mu \mathrm{g} / \mathrm{m}^{3}$ increase in $\mathrm{PM}_{2.5^{\circ}}{ }^{32}$ In addition, we found an association between exposure to $\mathrm{PM}_{2.5}$ and an increase in the risk of both incident ischemic 


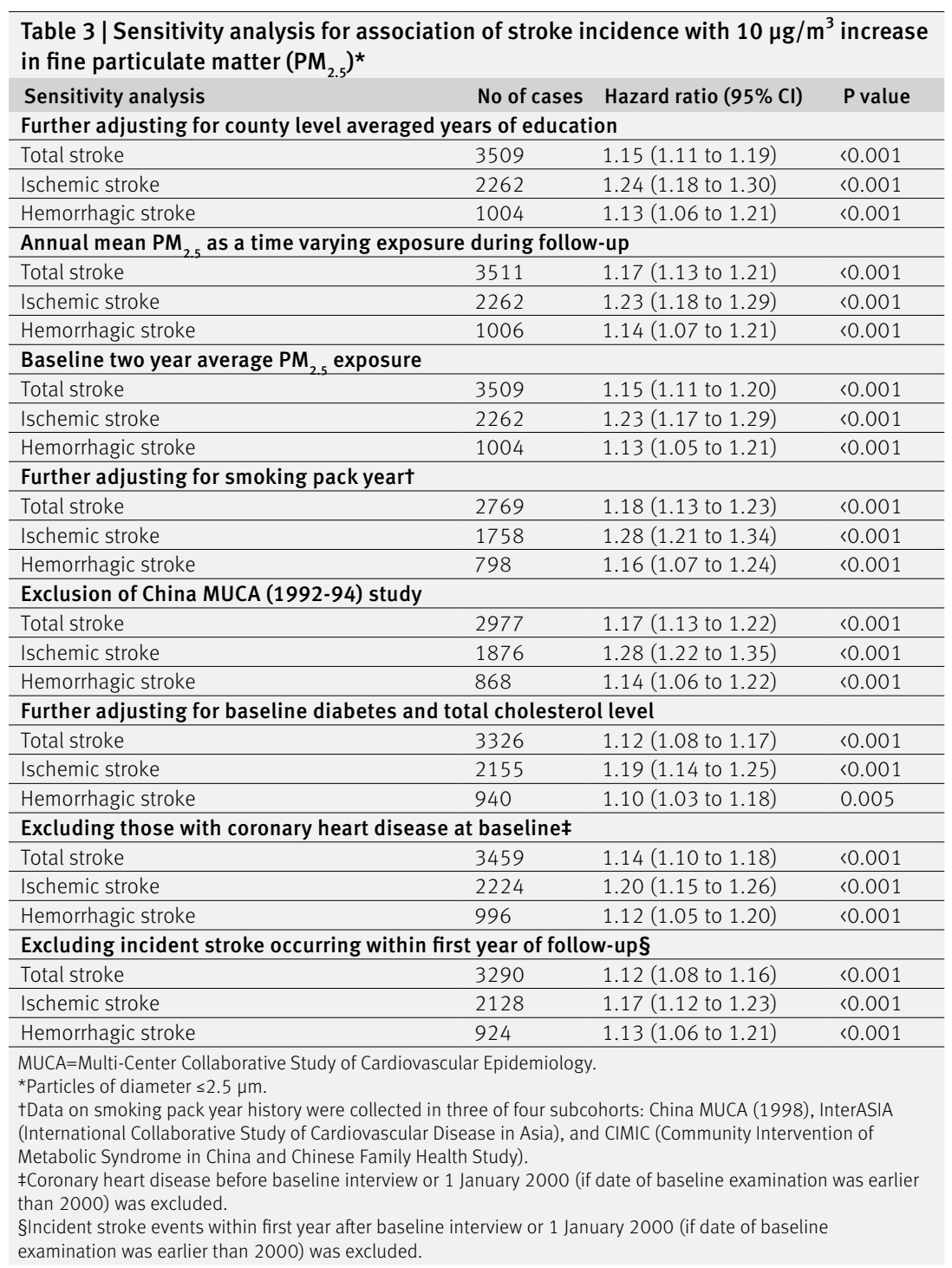

stroke and incident hemorrhagic stroke, which was rarely reported in previous cohort studies. ${ }^{4}$ Our results are in line with previous time series studies or case crossover studies that have reported an increased risk of both ischemic stroke and hemorrhagic stroke after short term exposure to particulate matter. ${ }^{33} 34$ In contrast, a smaller cohort study with short follow-up, conducted in Hong Kong, China found only statistically significant associations of long term exposure to $\mathrm{PM}_{2.5}$ at low concentrations (mean $35.8(\mathrm{SD} 2.4) \mu \mathrm{g} / \mathrm{m}^{3}$ ) with ischemic stroke but not with hemorrhagic stroke. ${ }^{4}$ These differences may have resulted from a relatively small sample size, variation of follow-up duration, narrow range of exposure to $\mathrm{PM}_{2,5}$, misclassification of stroke subtypes, and population characteristics. In subgroup analysis, although the $\mathrm{P}$ values for effect modification were not statistically significant in most subgroups, we found suggestive evidence of stronger associations between $\mathrm{PM}_{2.5}$ and incidence of ischemic stroke among elderly people and participants of normal body weight. These results were consistent with findings from the European Study of Cohorts for
Air Pollution Effects project. ${ }^{5}$ Further experimental studies were needed to understand the interaction effects between exposure to ambient $\mathrm{PM}_{2.5}$ and other risk factors in the development process of stroke.

Several researchers and practitioners have hypothesized differences between the mechanisms that link long term exposure to $\mathrm{PM}_{2,5}$ with ischemic and hemorrhagic stroke. ${ }^{33} 3536$ It was hypothesized that exposure to $\mathrm{PM}_{2.5}$ might result in platelet activation, promoting blood coagulation and thrombosis. ${ }^{37}$ In addition, long term exposure to $\mathrm{PM}_{2.5}$ might induce systemic inflammatory responses through increased release of plasma cytokines, leading to acceleration of atherosclerosis. ${ }^{37}$ Exposure to ambient $\mathrm{PM}_{2.5}$ could increase the risk of ischemic stroke through these pathophysiologic changes, whereas the mechanisms by which exposure to $\mathrm{PM}_{2.5}$ increase the risk of hemorrhagic stroke might include a triggering of arterial vasoconstriction and increases in blood pressure. ${ }^{38}$ Alternatively, endothelial dysfunction caused by air pollution might increase the vulnerability of brain vessels to rupture. ${ }^{33}$ Further basic medical research would provide insight into this casual pathway.

Estimating exposure-response relations between long term exposure to $\mathrm{PM}_{2.5}$ and risk of stroke is critical for assessing the burden of diseases and making public health policies. In the current study, we found almost linear exposure-response relations between $\mathrm{PM}_{2.5}$ concentration and stroke, overall and according to each subtype. The GBD Study, however, suggested a non-linear relationship between exposure to $\mathrm{PM}_{2.5}$ and stroke mortality, with steeper slopes at lower exposures, which level off at higher exposures. ${ }^{3}$ To consider the shape of exposure-response curves at high ambient concentrations, the Global Burden of Disease Study integrated risk estimates from studies in high income countries with lower ambient $\mathrm{PM}_{2.5}$ levels, as well as effect estimates for high concentrations derived from studies of household solid cooking fuel, secondhand smoke, and active smoking. ${ }^{39}$ This method was proposed without considering the variations in $\mathrm{PM}_{2.5}$ toxicity across different pollution sources (eg, ambient air pollution versus smoking), which may have influenced the effect estimates. ${ }^{3940}$ With a broader range of $\mathrm{PM}_{2.5}$ exposure (ie, 31.2-97.0 $\mu \mathrm{g} / \mathrm{m}^{3}$ ), our study filled the data gap at high ambient $\mathrm{PM}_{2.5}$ levels and raised the reliability of generalizations to China and other low and middle income countries, in terms of estimation of the burden of $\mathrm{PM}_{2.5}$ related disease.

\section{Strengths and limitations of this study}

This study has several advantages over previous research. First, we used data from large population based prospective cohorts with long follow-up and high quality outcome assessments. Second, our study participants were widely distributed across China, covering a wide range of geographic $\mathrm{PM}_{2.5}$ levels, from $31.2 \mu \mathrm{g} / \mathrm{m}^{3}$ to $97.0 \mu \mathrm{g} / \mathrm{m}^{3}$, which presented a valuable opportunity to assess exposure-response relations. Third, we used an advanced satellite based spatiotemporal model with high accuracy to estimate 
ambient $\mathrm{PM}_{2.5}$ levels at $1 \times 1 \mathrm{~km}$ resolution, which ensured accurate exposure assessment. Fourth, we collected data on multiple cardiovascular risk factors at the individual level, which allowed us to better control for potential confounders.

Some limitations of our study should be noted. First, we did not consider other air pollutants, meteorological factors, and environmental noise in our statistical models, because high quality and high resolution exposure estimates were unavailable. Second, we did not collect data around indoor air pollution sources such as household use of solid fuels. Third, we estimated exposures to ambient $\mathrm{PM}_{2.5}$ at the participants' residential address without considering their daily activities and location, which could result in misclassification of exposure. Indoor sources of air pollution and individual time-activity patterns are currently being collected and we will consider them in future analyses. Fourth, considering the limited statistical power, we did not perform analyses on subtypes of ischemic stroke.

\section{Conclusions and policy implications}

Long term exposure to ambient $\mathrm{PM}_{2.5}$ at relatively high ambient concentrations in China is positively and almost linearly associated with an increased risk of stroke, overall and by subtype. These findings are meaningful for both air quality related policy development and stroke prevention, not only in China, but also in other low and middle income countries.

\section{AUTHOR AFFILIATIONS}

${ }^{1}$ Department of Epidemiology, Fuwai Hospital, National Center for Cardiovascular Diseases, Chinese Academy of Medical Sciences and Peking Union Medical College, 167 Beilishi Road, Xicheng District, Beijing 100037, China

${ }^{2}$ Key Laboratory of Cardiovascular Epidemiology, Chinese Academy of Medical Sciences, Beijing, China

${ }^{3}$ School of Environment, Tsinghua University, Beijing, China

${ }^{4}$ Division of Epidemiology, Guangdong Provincial People's Hospital and Cardiovascular Institute, Guangzhou, China

${ }^{5}$ Department of Epidemiology and Biostatistics, School of Public Health, Nanjing Medical University, Nanjing, China

${ }^{6}$ Department of Cardiology, Fujian Provincial Hospital, Fuzhou, China

${ }^{7}$ Cardio-Cerebrovascular Control and Research Center, Institute of

Basic Medicine, Shandong Academy of Medical Sciences, Jinan, China

${ }^{8}$ Center for Chronic and Noncommunicable Disease Control and Prevention, Sichuan Center for Disease Control and Prevention, Chengdu, China

${ }^{9}$ Department of Prevention Medicine, Shenzhen University School of Medicine, Shenzhen, China

${ }^{10}$ Department of Environmental Health, Rollins School of Public Health, Emory University, Atlanta, GA, USA

We thank the staff and participants of the China-PAR project for their participation and contribution.

Contributors: $\mathrm{KH}$ and FLiang are joint first authors. DG contributed to the study design, implementation, manuscript discussion and critical revision. YLiu mainly contributed to $\mathrm{PM}_{25}$ exposure assessment protocol and methodology. JH contributed to critical revision of the manuscript. KH, FLiang, XY, FLiu, and JL analyzed the data and $\mathrm{KH}$ drafted the manuscript. FLiang and QX contributed to the PM exposure assessment. JL, QX, JChen, XLiu, JCao, CS, LY, FLu, XPW, LZ, XGW, YLi, DH, JH, and XLu collected and interpreted the data. All authors have read and approved the final manuscript. YLiu and DG are the guarantors. The corresponding author attests that all listed authors meet authorship criteria and that no others meeting the criteria have been omitted.
Funding: This work was supported by the National Key Research and Development Program of China (2017YFC0211703, and 2016YFC0206503), National Natural Science Foundation of China (91643208), Chinese Academy of Medical Science Innovation Fund for Medical Sciences (2017-12M-1-004), and the China Medical Board (15-220). The sources of funding had no role in study design, data collection, analyses, interpretation, and decision to submit the article for publication.

Competing interests: All authors have completed the ICMJE uniform disclosure form at www.icmje.org/coi_disclosure.pdf and declare: no support from any organization for the submitted work other than those described above; no financial relationships with any organizations that might have an interest in the submitted work in the previous three years; no other relationships or activities that could appear to have influenced the submitted work.

Ethical approval: This study was approved by the institutional review board at Fuwai Hospital in Beijing.

Data sharing: No additional data available.

The lead author (DG) affirms that the manuscript is an honest, accurate, and transparent account of the study being reported; that no important aspects of the study have been omitted; and that any discrepancies from the study as planned have been explained.

Publisher's note: Published maps are provided without any warranty of any kind, either express or implied. BM) remains neutral with regard to jurisdictional claims in published maps.

This is an Open Access article distributed in accordance with the Creative Commons Attribution Non Commercial (CC BY-NC 4.0) license, which permits others to distribute, remix, adapt, build upon this work non-commercially, and license their derivative works on different terms, provided the original work is properly cited and the use is non-commercial. See: http://creativecommons.org/licenses/ by-nc/4.0/.

1 World Health Organization. Ambient air pollution. World Health Organization website: www.who.int/airpollution/ambient/en/. (accessed on 04.10.2019)

2 Stanaway ID, Afshin A, Gakidou E et al, GBD 2017 Risk Factor Collaborators. Global, regional, and national comparative risk assessment of 84 behavioural, environmental and occupational, and metabolic risks or clusters of risks for 195 countries and territories, 1990-2017: a systematic analysis for the Global Burden of Disease Study 2017. Lancet 2018;392:1923-94. doi:10.1016/S01406736(18)32225-6

3 Cohen Al, Brauer M, Burnett R, et al. Estimates and 25-year trends of the global burden of disease attributable to ambient air pollution: an analysis of data from the Global Burden of Diseases Study 2015. Lancet 2017:389:1907-18. doi:10.1016/S01406736(17)30505-6

4 Qiu H, Sun S, Tsang H, et al. Fine particulate matter exposure and incidence of stroke: A cohort study in Hong Kong. Neurology 2017:88:1709-17. doi:10.1212/ WNL.0000000000003903

5 Stafoggia M, Cesaroni G, Peters A, et al. Long-term exposure to ambient air pollution and incidence of cerebrovascular events: results from 11 European cohorts within the ESCAPE project. Environ Health Perspect 2014;122:919-25. doi:10.1289/ehp.1307301

6 Miller KA, Siscovick DS, Sheppard L, et al. Long-term exposure to air pollution and incidence of cardiovascular events in women. $N$ Engl Med 2007;356:447-58. doi:10.1056/NEJMoa054409

7 Hart JE, Puett RC, Rexrode KM, Albert CM, Laden F. Effect modification of long-term air pollution exposures and the risk of incident cardiovascular disease in US women. J Am Heart Assoc 2015;4:e002301. doi:10.1161/JAHA.115.002301

8 Ma Z, Hu X, Sayer AM, et al. Satellite-based spatiotemporal trends in PM2.5 concentrations: China, 2004-2013. Environ Health Perspect 2016;124:184-92. doi:10.1289/ehp.1409481

9 Di Q, Kloog I, Koutrakis P, Lyapustin A, Wang Y, Schwartz I. Assessing PM2.5 exposures with high spatiotemporal resolution across the Continental United States. Environ Sci Technol 2016;50:4712-21. doi:10.1021/acs.est.5b06121

10 Lin H, Guo Y, Zheng Y, et al. Long-term effects of ambient PM2.5 on hypertension and blood pressure and attributable risk among older Chinese adults. Hypertension 2017;69:806-12. doi:10.1161/ HYPERTENSIONAHA.116.08839

11 Yin P, Brauer M, Cohen A, et al. Long-term fine particulate matter exposure and nonaccidental and cause-specific mortality in a large national cohort of Chinese men. Environ Health Perspect 2017:125:117002 doi:10.1289/EHP1673

12 Yang X, Li J, Hu D, et al. Predicting the 10-year risks of atherosclerotic cardiovascular disease in Chinese population: The China-PAR Project (Prediction for ASCVD Risk in China). Circulation 2016:134:1430-40. doi:10.1161/CIRCULATIONAHA.116.022367 
13 Liu F, Li J, Chen J, et al. Predicting lifetime risk for developing atherosclerotic cardiovascular disease in Chinese population: the ChinaPAR project. Sci Bull 2018:63:779-87. doi:10.1016/j.scib.2018.05.020

14 Wu Y, Liu X, Li X, et al, USA-PRC Collaborative Study of Cardiovascular and Cardiopulmonary Epidemiology Research Group, China Multicenter Collaborative Study of Cardiovascular Epidemiology Research Group. Estimation of 10-year risk of fatal and nonfatal ischemic cardiovascular diseases in Chinese adults. Circulation 2006;114:2217-25. doi:10.1161/ CIRCULATIONAHA.105.607499

15 The Collaborative Study Group on Trends of Cardiovascular Disease in China and Preventive Strategy. Current status of major cardiovascular risk factors in Chinese populations and their trends in the past two decades[in Chinese]. Zhonghua Xin Xue Guan Bing Za Zhi 2001;29:74-9.

16 Gu D, Reynolds K, Wu X, et al, InterASIA Collaborative Group. Prevalence of the metabolic syndrome and overweight among adults in China. Lancet 2005;365:1398-405. doi:10.1016/S0140 6736(05)66375-1

17 Perloff D, Grim C, Flack J, et al. Human blood pressure determination by sphygmomanometry. Circulation 1993;88:2460-70. doi:10.1161/01.CIR.88.5.2460

18 Xiao Q, Chang HH, Geng G, Liu Y. An ensemble machine-learning mode to predict historical PM2.5 concentrations in China from satellite data. Environ Sci Technol 2018;52:13260-9. doi:10.1021/acs.est.8b02917

19 Huang $\mathrm{K}$, Xiao $\mathrm{Q}$ Meng $\mathrm{X}$, et al. Predicting monthly high-resolution $\mathrm{PM}_{25}$ concentrations with random forest model in the North China Plain. Environ Pollut 2018;242(Pt A):675-83. doi:10.1016/j. envpol.2018.07.016

20 Lyapustin A, Wang Y, Laszlo I, et al. Multiangle implementation of atmospheric correction (MAIAC): 2. Aerosol algorithm. J Geophys Res 2011;116:D03211. doi:10.1029/2010JD014986

21 Di Q, Wang Y, Zanobetti A, et al. Air pollution and mortality in the medicare population. N Engl J Med 2017;376:2513-22. doi:10.1056/NEJMoa1702747

22 Chen H, Burnett RT, Kwong JC, et al. Spatial association between ambient fine particulate matter and incident hypertension. Circulation 2014;129:562-9. doi:10.1161/ CIRCULATIONAHA.113.003532

23 Grambsch PM, Therneau TM. Proportional hazards tests and diagnostics based on weighted residuals. Biometrika 1994;81:51526. doi:10.1093/biomet/81.3.515

24 Schwartz J, Coull B, Laden F, Ryan L. The effect of dose and timing of dose on the association between airborne particles and survival. Environ Health Perspect 2008;116:64-9. doi:10.1289/ehp.9955

25 Liang F, Yang X, Liu F, et al. Long-term exposure to ambient fine particulate matter and incidence of diabetes in China: A cohort study. Environ Int 2019;126:568-75. doi:10.1016/j.envint.2019.02.069

26 Huang K, Yang X, Liang F, et al. Long-term exposure to fine particulate matter and hypertension incidence in China. Hypertension 2019;73:1195-201. doi:10.1161/ HYPERTENSIONAHA.119.12666

27 Di Q, Dai L, Wang Y, et al. Association of short-term exposure to air pollution with mortality in older adults. JAMA 2017;318:2446-56. doi:10.1001/jama.2017.17923
28 Altman DG, Bland JM. Interaction revisited: the difference between two estimates. BMJ 2003;326:219. doi:10.1136/ bmi.326.7382.219

29 Atkinson RW, Carey IM, Kent AJ, van Staa TP, Anderson HR, Cook DG. Long-term exposure to outdoor air pollution and incidence of cardiovascular diseases. Epidemiology 2013:24:44-53. doi:10.1097/EDE.0b013e318276ccb8

30 Puett RC, Hart JE, Suh H, Mittleman M, Laden F. Particulate matter exposures, mortality, and cardiovascular disease in the health professionals follow-up study. Environ Health Perspect 2011;119:1130-5. doi:10.1289/ehp.1002921

31 Korek MJ, Bellander TD, Lind T, et al. Traffic-related air pollution exposure and incidence of stroke in four cohorts from Stockholm. J Expo Sci Environ Epidemiol 2015;25:517-23. doi:10.1038/ jes.2015.22

32 Scheers H, Jacobs L, Casas L, Nemery B, Nawrot TS. Long-term exposure to particulate matter air pollution is a risk factor for stroke: Meta-analytical evidence. Stroke 2015;46:3058-66. doi:10.1161/ STROKEAHA.115.009913

33 Yorifuji T, Kawachi I, Sakamoto T, Doi H. Associations of outdoor air pollution with hemorrhagic stroke mortality. J Occup Environ Med 2011:53:124-6. doi:10.1097/JOM.0b013e3182099175

34 Tsai SS, Goggins WB, Chiu HF, Yang CY. Evidence for an association between air pollution and daily stroke admissions in Kaohsiung, Taiwan. Stroke 2003;34:2612-6. doi:10.1161/01. STR 0000095564.33543 .64

$35 \mathrm{Lin} \mathrm{H,} \mathrm{Tao} \mathrm{J,} \mathrm{Du} \mathrm{Y,} \mathrm{et} \mathrm{al.} \mathrm{Differentiating} \mathrm{the} \mathrm{effects} \mathrm{of} \mathrm{characteristics}$ of PM pollution on mortality from ischemic and hemorrhagic strokes. Int J Hyg Environ Health 2016;219:204-11. doi:10.1016/j. ijheh.2015.11.002

36 Shah AS, Lee KK, McAllister DA, et al. Short term exposure to air pollution and stroke: systematic review and meta-analysis. BM/ 2015:350:h1295 doi:10.1136/bmi.h1295

37 Liu H, Tian Y, Xu Y, et al. Association between ambient air pollution and hospitalization for ischemic and hemorrhagic stroke in China: A multicity case-crossover study. Environ Pollut 2017;230:234-41. doi:10.1016/j.envpol.2017.06.057

38 Brook RD, Sun Z, Brook JR, et al. Extreme air pollution conditions adversely affect blood pressure and insulin resistance: the air pollution and cardiometabolic disease study. Hypertension 2016;67:77-85. doi:10.1161/ HYPERTENSIONAHA.115.06237

39 Burnett RT, Pope CA3rd, Ezzati M, et al. An integrated risk function for estimating the global burden of disease attributable to ambient fine particulate matter exposure. Environ Health Perspect 2014;122:397403. doi:10.1289/ehp.1307049

40 Pope CA3rd, Cohen AJ, Burnett RT. Cardiovascular disease and fine particulate matter: lessons and limitations of an integrated exposureresponse approach. Circ Res 2018;122:1645-7. doi:10.1161/ CIRCRESAHA.118.312956

Supplementary information: details of cohort and additional table and figure 